\title{
U⿱宀⿻三丨口
}

\section{Self-assembly in dilute mixtures of non-ionic and anionic surfactants and rhamnolipid biosurfactant}

Liley, J., Thomas, R. K., Tucker, I. M., Petkov, J. T., Stevebson, P. S., Banat, I. M., Marchant, R., Rudden, M., Terry, A., \& Gtillo, I. (2016). Self-assembly in dilute mixtures of non-ionic and anionic surfactants and rhamnolipid biosurfactant. Journal of Colloid and Interface Science, 487, 493-503.

https://doi.org/10.1016/j.jcis.2016.10.071

Link to publication record in Ulster University Research Portal

Published in:

Journal of Colloid and Interface Science

Publication Status:

Published online: 26/10/2016

DOI:

10.1016/j.jcis.2016.10.071

\section{Document Version}

Publisher's PDF, also known as Version of record

\section{General rights}

Copyright for the publications made accessible via Ulster University's Research Portal is retained by the author(s) and / or other copyright owners and it is a condition of accessing these publications that users recognise and abide by the legal requirements associated with these rights.

\section{Take down policy}

The Research Portal is Ulster University's institutional repository that provides access to Ulster's research outputs. Every effort has been made to ensure that content in the Research Portal does not infringe any person's rights, or applicable UK laws. If you discover content in the Research Portal that you believe breaches copyright or violates any law, please contact pure-support@ulster.ac.uk. 


\title{
Self-assembly in dilute mixtures of non-ionic and anionic surfactants and rhamnolipd biosurfactants
}

\author{
J.R. Liley ${ }^{\mathrm{a}, 1}$, J. Penfold ${ }^{\mathrm{a}, \mathrm{b}, *}$, R.K. Thomas ${ }^{\mathrm{a}}$, I.M. Tucker ${ }^{\mathrm{c}}$, J.T. Petkov ${ }^{\mathrm{c}, 2}$, P.S. Stevenson ${ }^{\mathrm{c}}$, I.M. Banat ${ }^{\mathrm{d}}$, \\ R. Marchant ${ }^{\mathrm{d}}$, M. Rudden ${ }^{\mathrm{d}}$, A. Terry ${ }^{\mathrm{b}}$, I. Grillo ${ }^{\mathrm{e}}$ \\ a Physical and Theoretical Chemistry Laboratory, Oxford University, South Parks Road, Oxford, UK \\ b ISIS, STFC, Rutherford Appleton Laboratory, Chilton, Didcot, Oxon, UK \\ ${ }^{c}$ Unilever Research and Development Laboratory Port Sunlight, Quarry Road East, Bebington, Wirral, UK \\ ${ }^{\mathrm{d}}$ School of Bio-medical Sciences, University of Ulster, Coleraine, Northern Ireland, UK \\ e Insitut-Laue Langevin, 71 Avenue des martyrs, CS 20156, 38042 Grenoble Cedex 09, France
}

\section{H I G H L I G H T S}

- Self-assembly of ternary and 5-component surfactant mixtures studied.

- In ternary mixtures, scattering data modelled as globular interacting micelles.

- In ternary mixtures, variation in aggregation number implies micelle composition close to solution composition.

- In 5-component mixture addition of rhamnolipid biosurfactants affects evolution in phase behaviour.

- For rhamnolipid rich compositions transition from micelle to lamellar/ micellar co-existence occurs.

- Transition associated with synergistic packing effects.

\section{A R T I C L E I N F O}

\section{Article history:}

Received 12 October 2016

Revised 24 October 2016

Accepted 25 October 2016

Available online 26 October 2016

\section{Keywords:}

Mixed surfactants

Biosurfactants

Self-assembly

Mixed micelles

Small angle neutron scattering
G R A P H I C A L A B S T R A C T

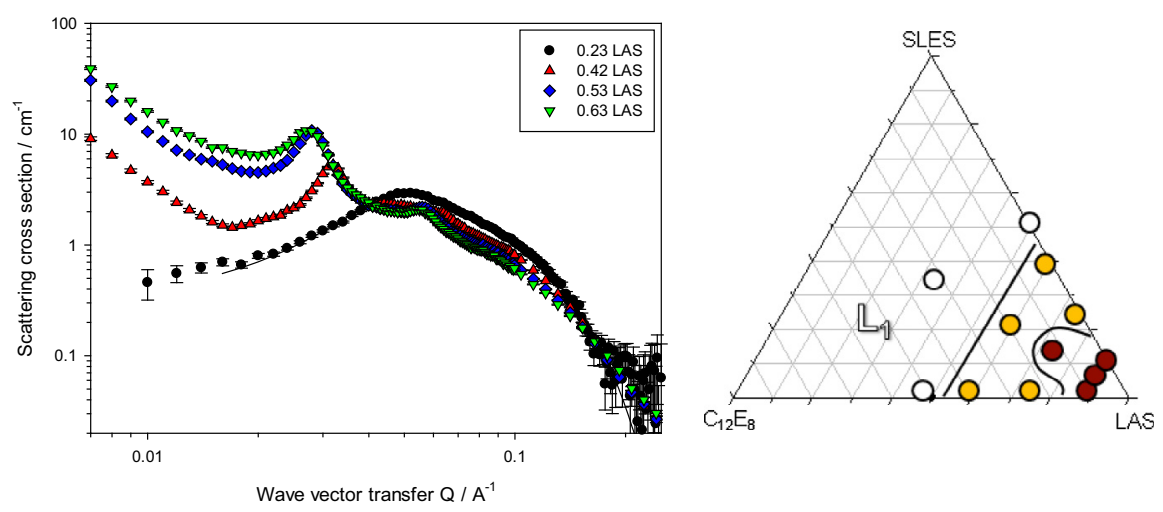

\begin{abstract}
A B S T R A C T
The self-assembly of dilute aqueous solutions of a ternary surfactant mixture and rhamnolipid biosurfactant/surfactant mixtures has been studied by small angle neutron scattering. In the ternary surfactant mixture of octaethylene glycol monododecyl ether, $\mathrm{C}_{12} \mathrm{E}_{8}$, sodium dodecyl 6-benzene sulfonate, LAS, and sodium dioxyethylene monododecyl sulfate, SLES, small globular interacting micelles are observed over the entire composition and concentration range studied. The modelling of the scattering data strongly supports the assumption that the micelle compositions are close to the solution compositions. In the 5-component rhamnolipid/surfactant mixture of the mono-rhamnose, R1, di-rhamnose, R2, rhamnolipids with $\mathrm{C}_{12} \mathrm{E}_{8} / \mathrm{LAS} / \mathrm{SLES}$, globular micelles are observed over much of the concentration and composition range studied. However, for solutions relatively rich in rhamnolipid and LAS, lamellar/micellar coexistence is observed. The transition from globular to more planar structures arises from a synergistic packing in the 5 component mixture. It is not observed in the individual components nor in the ternary $\mathrm{C}_{12} \mathrm{E}_{8} / \mathrm{LAS} / \mathrm{SLES}$ mixture at these relatively low concentrations. The results provide an insight into how
\end{abstract}

\footnotetext{
* Corresponding author at: Physical and Theoretical Chemistry Laboratory, Oxford University, South Parks Road, Oxford, UK. E-mail address: jeff.penfold@stfc.ac.uk (J. Penfold).

1 Current address: LGC, Queens Road, Teddington, Middlesex TW11 OLY, UK.

2 Current address: Lonza UK, GB-Blackley, Manchester, LANCS M9 8ES, UK.
} 
synergistic packing effects can occur in the solution self-assembly of complex multi-component surfactant mixtures, and give rise to an unexpected evolution in the phase behaviour.

(c) 2016 Elsevier Inc. All rights reserved.

\section{Introduction}

A wide variety of different biosurfactants are produced by different bacteria. Their natural role has long been of some interest [1], but increasingly their use in biodegradable and biosustainable surfactant based products has become a focus of attention [2-6]. One of the most commonly studied and exploited classes of biosurfactants are the glycolipids $[7,8]$, which are disaccharides that are acetylated by long chain fatty acids. The rhamnolipids are one of the most extensively studied and most promising biosurfactant [9]. In addition to the advantages of biosustainable and biodegradable products, the lower toxicity, higher tolerance to $\mathrm{pH}$, temperature and salinity and their production from non-petrochemical based sources enhance their potential for many applications. Hence they have already been exploited in niche areas associated with enhanced oil recovery [4], bioremediation [6], in specialised healthcare and cosmetics applications [7], and in some aspects of detergency [10]. More widespread incorporation into surfactant based products is limited by the need for improved yields and scale up, ease of purification, and the requirement for non-pathogenic bacterial sources $[11,12]$.

One of the more immediate and promising routes to the wider use of biosurfactants, and especially rhamnolipids, in a wider range of surfactant based products is their incorporation with surfactants from conventional sources. The adsorption and self-assembly of rhamnolipids has been addressed in a range of recent studies [13-24], but there is relatively little information on their behaviour with other surfactants [25-27]. In contrast, in the field of conventional surfactants the study of surfactant mixing is a mature activity, and many of the basic phenomena associated with ideal and non-ideal mixing are well established experimentally and theoretically [28-33]. More recently the application of new experimental methods, and particularly small angle neutron scattering, SANS, and neutron reflectivity, NR, to probe surfactant mixing in micelles and at interfaces has provided new insights [34,35], and challenged some aspects of the current thermodynamic treatments of nonideal mixing $[35,36]$.

NR has been used to study the adsorption of a range of relevant binary surfactant, some ternary surfactant [37], and some multicomponent surfactant [38] mixtures at the air-water interface [34]. The recent studies on the adsorption of the ternary mixture $\mathrm{C}_{12} \mathrm{E}_{8} /$ LAS/SLES [39] and the 5-component mixture of R1/R2/ $\mathrm{C}_{12} \mathrm{E}_{8} / \mathrm{LAS} / \mathrm{SLES}$ [40] are of particular relevance to this study. SANS studies on multi-component mixed surfactant micelles are less common, but a number of recent studies are particularly relevant $[25,26,41-44]$. In the absence of electrolyte the LAS/non-ionic [43] and SLES/non-ionic [44] mixed micelles are globular and their aggregation numbers are consistent with a micelle composition close to the solution composition. This is observed in a range of ionic/non-ionic surfactant mixtures at concentrations >> critical micellar concentration, cmc [41-44]. At lower surfactant concentrations, as the cmc is approached, the micelle composition evolves and becomes richer in the more surface active components $[34,41,42]$; as predicted for non-ideal and ideal mixing by the pseudo-phase approximation [30]. Hence in general at concentrations well above the $\mathrm{cmc}$ the mixed micelle structures reflect the structures of the pure component micelles. In the examples cited above, the preferred curvature of LAS, SLES, SDS and the nonionic cosurfactants $\mathrm{C}_{12} \mathrm{E}_{6}, \mathrm{C}_{12} \mathrm{E}_{8}$ and $\mathrm{C}_{12} \mathrm{E}_{12}$ favour small globular structures at relatively low surfactant concentrations. LAS shows a slightly different trend at higher concentrations $(\geqslant 100 \mathrm{mM})$ and has a greater tendency towards more planar structures $[43,45]$; and this has an impact on mixed micelle structures involving LAS. Hence in such cases, the competition between the relative preferred curvature in different surfactant components will determine the evolution in the micelle structure. This is observed more acutely in the rhamnolipid based systems [24,25]. R1 and R2 both form globular micelles at low surfactant concentrations $\leqslant 20 \mathrm{mM}$. $\mathrm{R} 2$, with the larger dirhamnose headgroup, remains globular up to relatively high surfactant concentrations. R1, with the smaller monorhamnose headgroup, has a lower preferred curvature and forms planar structures (lamellar or vesicular) at concentrations $>20 \mathrm{mM}$. In R1/R2 mixtures the micelles remain globular at low surfactant concentrations, $\leqslant 20 \mathrm{mM}$; but a higher concentrations an evolution in the structure from globular to planar structures results from the competition between the preferred curvature associated with R1 and R2 [24]. A similar tension is observed in R1/LAS and R2/LAS mixtures [25]. R2/LAS mixtures are predominantly globular, apart from LAS rich compositions at relatively high surfactant concentrations. R1/LAS mixtures are however predominantly planar. In the R1/R2/LAS ternary mixture the evolution in the self-assembly is complex [25], and arises from the competition between the three different preferred curvatures.

These recent examples highlight the potential for a complex evolution in micelle structure in multi-component surfactant mixtures, and which are not necessarily easily predicted. In this paper we have used SANS to probe the micelle structure and the role of the relative preferred curvature on that structure in the biosurfactant/surfactant mixture of $\mathrm{R} 1 / \mathrm{R} 2 / \mathrm{C}_{12} \mathrm{E}_{8} / \mathrm{LAS} / \mathrm{SLES}$. The associated binary mixtures of $\mathrm{C}_{12} \mathrm{E}_{8}$, LAS and SLES and the ternary mixtures of $\mathrm{C}_{12} \mathrm{E}_{8}$, LAS and SLES in the absence of rhamnolipid, are also studied. The results provide an important insight into the evolution in the bulk structures, and have important consequences for the formulation of biosurfactant/surfactant mixtures.

\section{Experimental details}

\subsection{Small angle neutron scattering}

In small angle scattering the pattern of the scattering intensity with wave vector transfer, $Q$ (where $Q$ is defined as $Q=4 \pi / \lambda \sin (\theta)$, $\lambda$ is the neutron wavelength, and $2 \theta$ is the scattering angle) from a micellar solution contains information about the micelle structure and inter-micellar interactions [46]. For a solution of globular polydisperse interacting micelles the scattered intensity can be expressed in the 'decoupling approximation' as [46],

$I(Q)=n\left[S(Q)\left|\langle F(Q)\rangle_{Q}\right|^{2}+\left\langle|F(Q)|^{2}\right\rangle_{Q}-\left|\langle F(Q)\rangle_{Q}\right|^{2}\right]$

where the average $<>_{\mathrm{Q}}$ denotes averaging over micelle sizes and orientations, $\mathrm{n}$ is the micelle number density, $\mathrm{F}(\mathrm{Q})$ the micelle form factor and $\mathrm{S}(\mathrm{Q})$ the inter-micellar structure factor. $\mathrm{S}(\mathrm{Q})$ is modelled using the rescaled mean spherical approximation, RMSA, calculated for a repulsive screened coulombic potential $[47,48]$. As such, $S(Q)$ is defined by the micelle surface charge, $z$, the micelle number density, $n$, the micelle diameter, and the Debye-Hückel inverse screening length, $\kappa^{-1}[47]$. 
The SANS measurements were made on three different small angle scattering diffractometers, LOQ [49] and SANS2D [50] at the ISIS neutron source, and D33 [51] at the Institute Laue Langevin. On LOQ and SANS2D the measurements were made using the white beam time of flight method. On LOQ a neutron wavelength range of $2-10 \AA$ and a sample to detector distance of $4.15 \mathrm{~m}$ was used to cover a $\mathrm{Q}$ range of $0.008-0.25 \AA^{-1}$. On SANS2D a $Q$ range of $0.01-0.35 \AA^{-1}$ was covered using neutron wavelengths of 2-12 Å and a sample to detector distance of $2.42 \mathrm{~m}$. On D33 the measurements were made in monochromatic mode with a neutron wavelength of $4.6 \AA(\Delta \lambda / \lambda \sim 10 \%)$ and two detector arrays at 2 and $12 \mathrm{~m}$ from the sample position to cover a $\mathrm{Q}$ range of $0.004-0.3 \AA^{-1}$. In all cases an $8 \mathrm{~mm}$ diameter beam was used, and the measurement times were $\sim 10-20$ min per sample for $1 \mathrm{~mm}$ path length samples. The scattering from the cell and solvent were subtracted from the data. The data were normalised to the detector response and spectral distribution of the incident beam to establish the scattered intensity, $\mathrm{I}(\mathrm{Q})$, as an absolute scattering cross-section using standard procedures [52,53].

\subsection{Materials and measurements made}

All the surfactant solution were prepared using the hydrogeneous form of the surfactants with $\mathrm{D}_{2} \mathrm{O}$ as the solvent. All the solutions were measured at $25^{\circ} \mathrm{C}$ and in $10^{-6} \mathrm{M} \mathrm{NaOH}$ to provide a nominal $\mathrm{pH}$ of 8 . The solutions were contained in $1 \mathrm{~mm}$ path length Hellma quartz spectrophotometer cells. All cells and associated glassware used to prepare the solutions were cleaned in dilute (2\%) Decon90 solution and rinsed in MilliQ Ultrapure water, rinsed in acetone and dried in an air flow. The $\mathrm{C}_{12} \mathrm{E}_{8}$ was obtained from Nikkol and used as supplied. The LAS was synthesised and purified as described elsewhere [43]. The SLES was synthesised and purified by recrystallization from ethanol/acetone mixtures as described by $\mathrm{Xu}$ et al. [54]. The rhamnolipids 1-rhamnosyl-1-rhamnosyl- $\beta$ hydroxydecanol- $\beta$-hydroxydecanoate, R1, and 1-rhamnosyl- $\beta$ hydroxydecanol- $\beta$-hydroxydecanoate, R2, were obtained from Jeneil Biosurfactant Co and separated into pure R1 and R2 components as described elsewhere [24], and the structure of R1 and R2 are shown in Fig. 1.

The binary and ternary mixtures of $\mathrm{C}_{12} \mathrm{E}_{8}$, LAS and SLES were measured at surfactant concentrations of 10,25 and $50 \mathrm{mM}$ and over a wide range of compositions. The 5-component $\mathrm{R} 1 / \mathrm{R} 2 / \mathrm{C}_{12} \mathrm{E}_{8} / \mathrm{LAS} / \mathrm{SLES}$ mixtures were also measured at 10,25 and $50 \mathrm{mM}$. These measurements were made for a range of $\mathrm{C}_{12} \mathrm{E}_{8} / \mathrm{LAS} / \mathrm{SLES}$ compositions in which 20 or $30 \mathrm{~mol} \%$ of the ternary surfactant mixture is replaced by an R1/R2 mixture. The measurements were made for both $1: 1$ and $2: 1 \mathrm{R} 1 / \mathrm{R} 2$ mixtures. The measurements of the mixtures of $\mathrm{C}_{12} \mathrm{E}_{8}$, LAS and SLES and the 5 -component mixtures were made on LOQ and SANS2D, with the measurements at the lower surfactant concentrations predominantly on SANS2D. D33 was used for measurements of the 5-component mixtures which were rich in LAS.

\section{Results and discussion}

For the binary and ternary surfactant mixtures of $\mathrm{C}_{12} \mathrm{E}_{8}$, LAS and SLES and for some of the 5-component R1/R2/ $\mathrm{C}_{12} \mathrm{E}_{8} / \mathrm{LAS} / \mathrm{SLES}$ mixtures the form of the self-assembly is identified from the scattering pattern. The data consists of regions of globular interacting micelles or a mixed micellar/lamellar (vesicular) phase. The data for the globular interacting micelles are analysed quantitatively using the standard 'core and shell' model for globular micelles [46] using Eq. (1). The micelle form factor, $F(Q)$, is given by [46],

$F(Q)=V_{1}\left(\rho_{1}-\rho_{2}\right) F_{0}\left(Q r_{1}\right)+V_{2}\left(\rho_{2}-\rho_{s}\right) F_{0}\left(Q r_{2}\right)$

$F_{0}\left(Q r_{i}\right)=3\left[\sin \left(Q r_{i}\right)-Q r_{i} \cos \left(Q r_{i}\right)\right] /\left(Q r_{i}\right)^{3}$

and $\mathrm{r}_{1}, \mathrm{r}_{2}$ are the core and shell radii, $V_{i}=4 \pi r_{i}^{3} / 3, \rho_{1}, \rho_{2}$ and $\rho_{\mathrm{s}}$ are the scattering length densities of the micelle core and shell, and of the solvent $\left(\rho_{\mathrm{i}}=\mathrm{N}_{\mathrm{i}} \mathrm{b}_{\mathrm{i}}\right.$ and $\mathrm{N}_{\mathrm{i}}, \mathrm{b}_{\mathrm{i}}$ are the number density and the scattering length of the $i^{\text {th }}$ component). Molecular and packing constraints are used to define and constrain the core and shell model. The inner core has a radius $r_{1}$ which contains the surfactant alkyl chains in a volume constrained to have a maximum radius equal to the fully extended alkyl chain length, $l_{c}$, of the surfactant. A model parameter, ext, allows some variation in the packing constraint, and is generally in the region 1.0-1.3, For micelle aggregation numbers, $v$, greater than can be accommodated in a sphere of radius $l_{c}$ a prolate ellipsoid shape is assumed, with core dimensions of $r_{1}$ and $r_{1}$. ee, where ee is the ellipticity ratio. For spherical or ellipsoidal shapes the outer shell radius, $r_{2}$, is constrained to contain the headgroups and associated hydration. The surfactant mixing is taken into account by using a composition weighted average of the parameters associated with each surfactant and assuming that the micelle composition reflects the solution composition. $\mathrm{S}(\mathrm{Q})$ is calculated using the RMSA, as described earlier. From the known molecular volumes and dimensions and associated scattering lengths, the scattering is calculated on an absolute scale, compared with the data and evaluated by least squares. An acceptable model requires that the functional form of the scattering is reproduced and the absolute scattering is predicted to within $\pm 20 \%$. The data for the mixed micellar/lamellar (vesicular) phase are not analysed quantitatively.

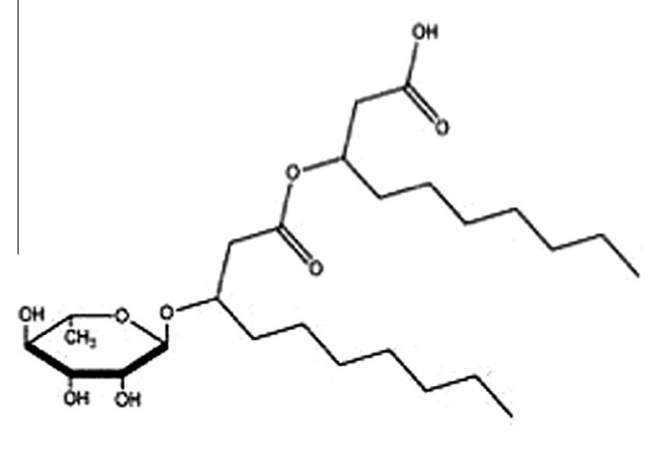

(a) R1

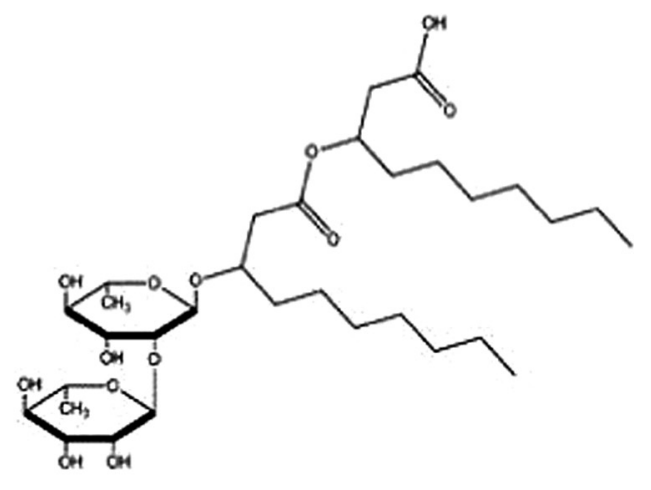

(b) R2

Fig. 1. Structure of the rhamnolipids R1, and R2. 


\subsection{Binary mixtures}

SANS measurements were made for the binary mixtures of $\mathrm{C}_{12} \mathrm{E}_{8} / \mathrm{SLES}, \mathrm{C}_{12} \mathrm{E}_{8} /$ LAS and LAS/SLES at surfactant concentrations of 10,25 and $50 \mathrm{mM}$ and over a range of surfactant compositions. The data presented in Fig. 2 are for the $\mathrm{C}_{12} \mathrm{E}_{8} / \mathrm{SLES}$ mixture. In Fig. 2a the data are for $0.5 / 0.5 \mathrm{~mol}$ ratio of $\mathrm{C}_{12} \mathrm{E}_{8} / \mathrm{SLES}$ at surfactant concentrations of 10,25 , and $50 \mathrm{mM}$. In Fig. $2 \mathrm{~b}$ the data are from a $25 \mathrm{mM}$ solution of $\mathrm{C}_{12} \mathrm{E}_{8} / \mathrm{SLES}$ at solution compositions of $0.75 / 0.25,0.5 / 0.5,0.25 / 0.75$, and $0.1 / 0.9 \mathrm{~mol}$ ratios.

The data in Fig. 2 are consistent with relatively small globular interacting micelles, and are well described by the core and shell model of interacting micelles [46]. In Fig. 2a the interaction peaks in the data shifts to lower $Q$ values as the micelle number density increases, and the scattering intensity increases as the total surfactant concentration increases. In Fig. $2 \mathrm{~b}$ the variation in the scattering pattern with composition at a fixed surfactant concentration reflects the change in the aggregation number and form factor from SLES to $\mathrm{C}_{12} \mathrm{E}_{8}$ rich compositions. The key model parameters are summarised in Table 1 and Table S1 in the Supporting Information.

At a fixed composition (see Fig. 2a) as the surfactant concentration increases there is a modest increase in the micelle aggregation number. At a fixed concentration, as the solution composition varies from SLES to $\mathrm{C}_{12} \mathrm{E}_{8}$ rich the aggregation number varies more significantly, but dependent upon the surfactant concentration. At a surfactant concentration of $10 \mathrm{mM}$ it increases from 67 to 101. At surfactant concentrations of 25 and $50 \mathrm{mM}$ the increase is more modest, and is from $\sim 90-100$. These changes reflect the aggregation number of the pure component micelles. SLES has an aggregation number $\sim 75$ at $10 \mathrm{mM}$ and $\sim 90$ at $25 \mathrm{mM}$ [54]. The aggregation number for $\mathrm{C}_{12} \mathrm{E}_{8}$ is $\sim 110$ and varies little with surfactant concentration in the concentration range measured here [43]. The variation in the degree of micelle ionisation, $\delta$, (where $\delta=z / v$ ) reflects the change from $\mathrm{C}_{12} \mathrm{E}_{8}$ to SLES rich micelles. For the $\mathrm{C}_{12} \mathrm{E}_{8}$ rich compositions the degree of ionisation is systematically lower,

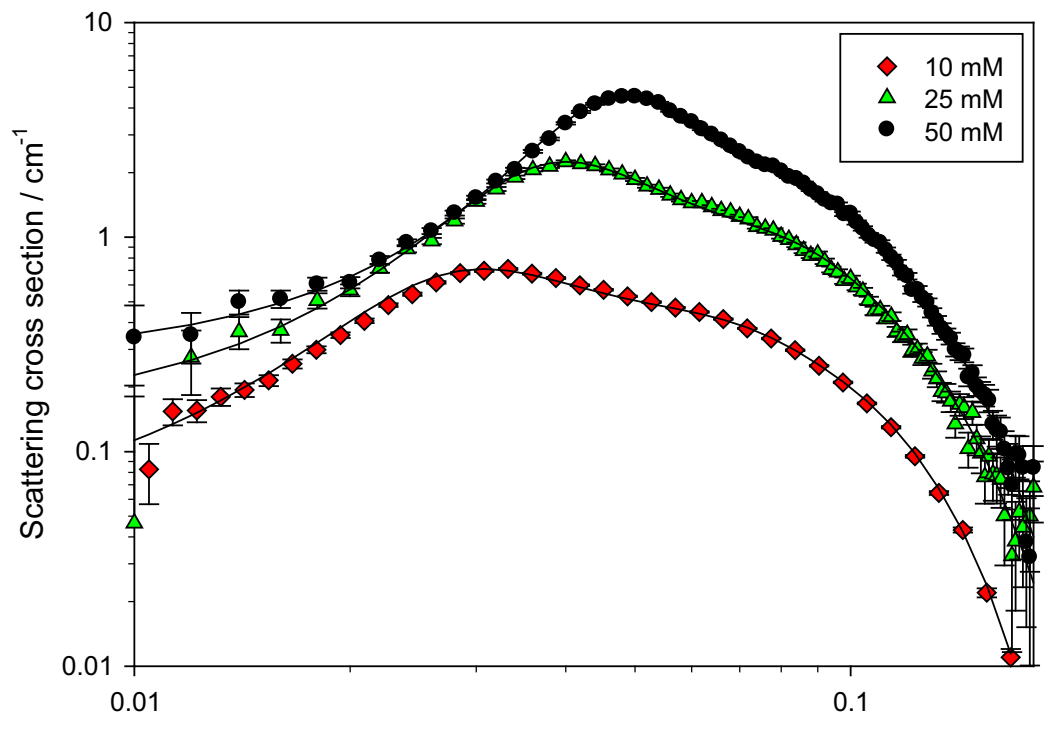

(a) Wave vector transfer $\mathrm{Q} / \mathrm{A}^{-1}$

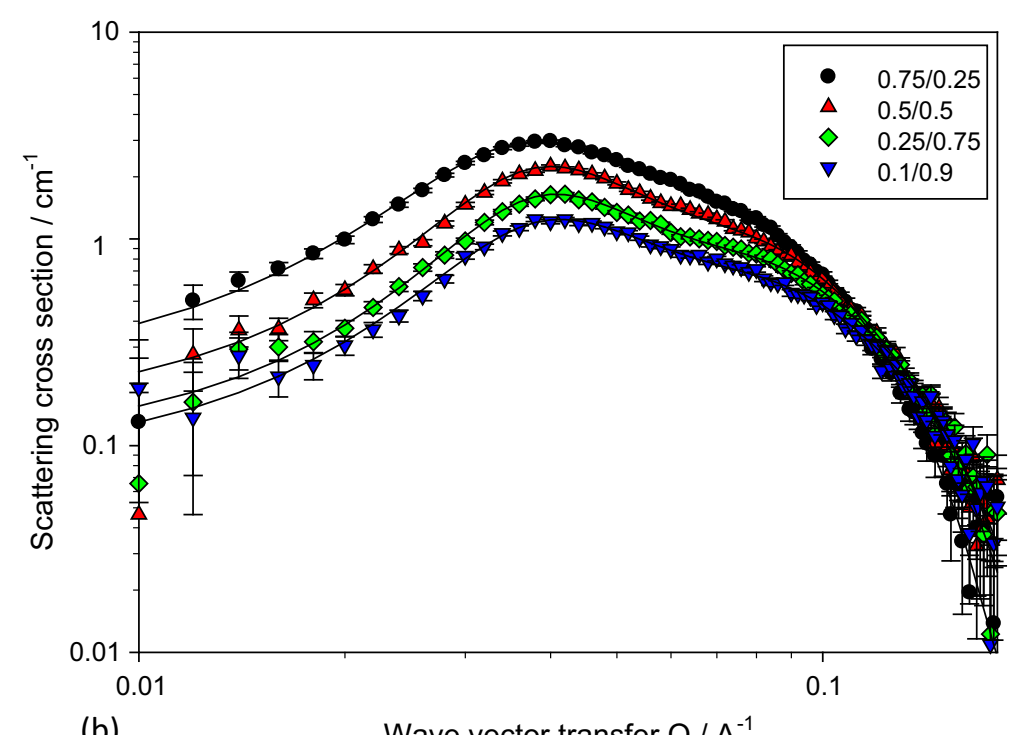

(b)

Wave vector transfer $Q / A^{-1}$

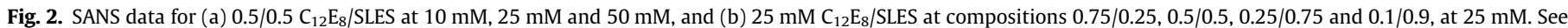

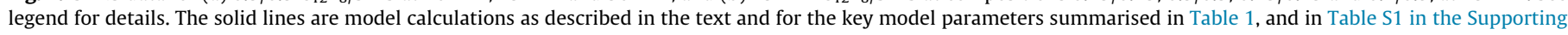
Information. 
Table 1

Key model parameters from core and shell model analysis of SANS data for $C_{12} E_{8} /$ SLES mixed surfactants.

\begin{tabular}{|c|c|c|c|c|c|c|c|c|c|}
\hline \multirow[t]{2}{*}{$\begin{array}{l}\text { Surfactant } \\
\text { concentration (mM) }\end{array}$} & \multicolumn{2}{|c|}{$\begin{array}{l}\text { Solution composition } \\
\left(C_{12} E_{8} / \text { SLES mole ratio }\right) \\
\end{array}$} & \multirow[t]{2}{*}{$v( \pm 5)$} & \multirow[t]{2}{*}{$\mathrm{z}( \pm 1)$} & \multirow[t]{2}{*}{$\delta( \pm 0.02)$} & \multirow[t]{2}{*}{$\mathrm{r} 1( \pm 1 \AA ̊)$} & \multirow[t]{2}{*}{$\mathrm{r} 2( \pm 1 \AA ̊)$} & \multirow[t]{2}{*}{ ext $( \pm 0.05)$} & \multirow[t]{2}{*}{ ee $( \pm 0.02)$} \\
\hline & $\mathrm{C}_{12} \mathrm{E}_{8}$ & SLES & & & & & & & \\
\hline 10 & 0.5 & 0.5 & 82 & 16 & 0.20 & 18 & 23 & 1.10 & 1.42 \\
\hline 25 & 0.1 & 0.9 & 93 & 17 & 0.18 & 18 & 25 & 1.10 & 1.12 \\
\hline 25 & 0.25 & 0.75 & 92 & 19 & 0.21 & 18 & 23 & 1.10 & 1.16 \\
\hline 25 & 0.5 & 0.5 & 96 & 19 & 0.20 & 18 & 24 & 1.10 & 1.21 \\
\hline 25 & 0.75 & 0.25 & 109 & 15 & 0.14 & 18 & 25 & 1.10 & 1.37 \\
\hline 50 & 0.5 & 0.5 & 100 & 22 & 0.22 & 18 & 24 & 1.10 & 1.26 \\
\hline
\end{tabular}

similar to the trend reported for $\mathrm{SDS} / \mathrm{C}_{12} \mathrm{E}_{8}$ micelles [42]. However, the degree of ionisation for the SLES rich micelles is also relatively low compared to other ionic surfactant micelles. $\delta$ is $\sim 0.2$, whereas ionic micelles in general have a $\delta \sim 0.3$ to 0.35 [46]. This was discussed at length by Xu et al. [54,55], where it was observed that SLES is only relatively weakly dissociated.

Broadly similar data are observed for $\mathrm{C}_{12} \mathrm{E}_{8} /$ LAS and LAS/SLES surfactant mixtures, and the data are summarised in Tables S2 and S3 and Figs. S1 and S2 in the Supporting Information. For both the $\mathrm{C}_{12} \mathrm{E}_{8}$ /LAS and LAS/SLES mixtures the SANS data are again consistent with globular interacting micelles. The aggregation number for the $\mathrm{C}_{12} \mathrm{E}_{8} / \mathrm{LAS}$ mixture varies with solution composition and concentration from $\sim 70$ to $\sim 110$; whereas for the LAS/SLES mixture it varies from $\sim 45$ to $\sim 90$. As with the $\mathrm{C}_{12} \mathrm{E}_{8} / \mathrm{SLES}$ mixture these variations reflect the aggregation of the pure component micelles. For LAS the aggregation number is $\sim 30$ at $10 \mathrm{mM}, \sim 40$ at $25 \mathrm{mM}$ and $\sim 47$ at $50 \mathrm{mM}$ [43]. The greater variation in the aggregation number for the LAS containing mixtures reflect the much lower LAS aggregation number compared to that for SLES or $\mathrm{C}_{12} \mathrm{E}_{8}$. The degree of ionisation of the LAS/SLES and $\mathrm{LAS} / \mathrm{C}_{12} \mathrm{E}_{8}$ mixtures is low compared to other charged micelles, and is $\leqslant 0.2$. It is also especially low for $\mathrm{C}_{12} \mathrm{E}_{8}$ and SLES rich micelles, as was also observed for the $\mathrm{C}_{12} \mathrm{E}_{8} / \mathrm{SLES}$ micelles earlier. In all three binary mixtures, $\mathrm{C}_{12} \mathrm{E}_{8} / \mathrm{SLES}, \mathrm{LAS} / \mathrm{C}_{12} \mathrm{E}_{8}$ and LAS/SLES the quality of the model fits, in terms of the form of the scattering and the absolute scale of the scattering, are such that the assumption that the micelle composition reflects the solution composition is justified. Hence the variation in the micelle aggregation is a weighted average of the aggregation numbers associated with the pure micellar components

\subsubsection{Ternary mixtures}

SANS measurements were made for the ternary mixture of $\mathrm{C}_{12} \mathrm{E}_{8} /$ LAS/SLES at surfactant concentrations of 10,25 and $50 \mathrm{mM}$, and over a range of compositions. The compositions over which the measurements were made are summarised in the ternary diagram shown in Fig. 3.

All the SANS data for the ternary mixtures are consistent with the scattering from interacting globular micelles, and hence broadly similar to the data shown in Fig. 2. The SANS data for a $0.33 / 0.33 / 0.33 \mathrm{~mol}$ ratio mixture of $\mathrm{C}_{12} \mathrm{E}_{8} /$ LAS/SLES at surfactant concentrations of 10,25 and $50 \mathrm{mM}$, and the variation in the SANS data with composition at a surfactant concentration of $50 \mathrm{mM}$ are shown in Fig. S4a and b in the Supporting Information. A full summary of the key model parameters for the core and shell model fits to the ternary data can be found in Table S4 in the Supporting Information.

The key model parameters corresponding to the data shown in Fig. S3a and b are also summarised here in Tables 2 and 3.

At the fixed solution composition of $0.33 / 0.33 / 0.33 \mathrm{C}_{12} \mathrm{E}_{8} / \mathrm{LAS} /$ SLES (see Table 2) the aggregation number increases with increasing surfactant concentration, from $\sim 65$ to $\sim 90$ at the highest

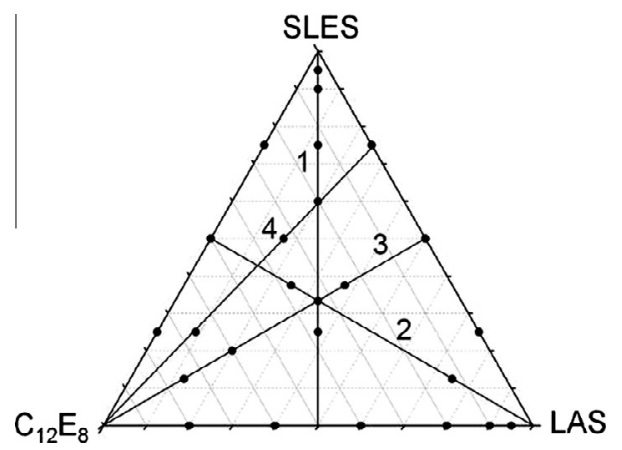

Fig. 3. Ternary $\mathrm{C}_{12} \mathrm{E}_{8} / \mathrm{LAS} / \mathrm{SLES}$ diagram, showing the points at which SANS measurements were made; where line 1 represents equal $C_{12} E_{8}$ and LAS mole fractions, line 2 equal $C_{12} E_{8}$ and SLES mole fractions, line 3 equal SLES and LAS mole fractions, line 4 differing $\mathrm{C}_{12} \mathrm{E}_{8}$, LAS and SLES mole fractions, and the edges of the triangle the binary mixtures.

surfactant concentration, and the degree of ionisation is relatively constant. At the fixed surfactant concentration of $50 \mathrm{mM}$ and variable $\mathrm{C}_{12} \mathrm{E}_{8} / \mathrm{LAS} / \mathrm{SLES}$ composition (see Table 3 ) the aggregation number increases as the solution composition becomes richer in the non-ionic $\mathrm{C}_{12} \mathrm{E}_{8}$ and the degree of ionisation decreases significantly.

The three lines or cuts through the ternary diagram shown in Fig. 3 are lines in which the composition of one of the components, SLES (line 1), LAS (line 2) and $\mathrm{C}_{12} \mathrm{E}_{8}$ (line 3 ) varies and the other two components have equal but varying compositions. Along the lines of increasing SLES or $\mathrm{C}_{12} \mathrm{E}_{8}$ composition the aggregation number increases, and for the line of increasing LAS composition it decreases; as shown in the data in Table S4. As observed for the binary mixtures the model fits are consistent with the assumption that the micelle composition reflects the solution composition, and the micelle aggregation numbers are again a weighted average of the pure components.

Hence, in general, in the binary and ternary mixtures the variation in the micelle aggregation number reflects the values of the pure component micelles of $\mathrm{C}_{12} \mathrm{E}_{8}$, LAS and SLES. This is illustrated more completely in Fig. 4, where the variation in aggregation number for the ternary mixtures as a function of solution composition over the entire composition range and concentrations measured are shown as colour contour ternary diagrams.

\subsection{5-component $R 1 / R 2 / C_{12} E_{8} / L A S / S L E S$ mixture}

SANS measurements were made for the 5-component R1/R2/ $\mathrm{C}_{12} \mathrm{E}_{8} / \mathrm{LAS} / \mathrm{SLES}$ mixture at surfactant concentrations of 10,25 and $50 \mathrm{mM}$. The measurements were made for variable $\mathrm{C}_{12} \mathrm{E}_{8} /$ LAS/SLES compositions, over a similar composition range to those used for the ternary mixture earlier. In the 5-component mixtures a fraction of the $C_{12} E_{8} /$ LAS/SLES ternary mixture is replaced by a 
Table 2

Key model parameters for core and shell model fit to SANS data for $0.33 / 0.33 / 0.33 \mathrm{~mol}$ ratio mixture of $\mathrm{C}_{12} \mathrm{E}_{8} / \mathrm{LAS} / \mathrm{SLES}$ at surfactant concentrations of 10,25 and 50 mM.

\begin{tabular}{|c|c|c|c|c|c|c|c|}
\hline Surfactant concentration (mM) & $v( \pm 5)$ & $\mathrm{z}( \pm 1)$ & $\delta( \pm 0.02)$ & $\mathrm{r} 1( \pm 1 \AA)$ & $\mathrm{r} 2( \pm 1 \AA)$ & $\operatorname{ext}( \pm 0.05)$ & ee $( \pm 0.02)$ \\
\hline 10 & 65 & 14 & 0.22 & 17 & 21 & 1.12 & 1.44 \\
\hline 25 & 83 & 16 & 0.19 & 19 & 26 & 1.45 & 1.00 \\
\hline 50 & 86 & 18 & 0.21 & 18 & 23 & 1.17 & 1.31 \\
\hline
\end{tabular}

Table 3

Key model parameters for core and shell model fit to SANS data for $\mathrm{C}_{12} \mathrm{E}_{8} / \mathrm{LAS} / \mathrm{SLES}$ mixture with different compositions at a surfactant concentration 50 mM.

\begin{tabular}{|c|c|c|c|c|c|c|c|c|c|}
\hline \multicolumn{3}{|c|}{$\begin{array}{l}\text { Solution composition } \\
\left(\mathrm{C}_{12} \mathrm{E}_{8} / \text { LAS / SLES mole ratio) }\right.\end{array}$} & \multirow[t]{2}{*}{$v( \pm 5)$} & \multirow[t]{2}{*}{$\mathrm{z}( \pm 1)$} & \multirow[t]{2}{*}{$\delta( \pm 0.02)$} & \multirow[t]{2}{*}{$\mathrm{r} 1( \pm 1 \AA)$} & \multirow[t]{2}{*}{$\mathrm{r} 2( \pm 1 \AA)$} & \multirow[t]{2}{*}{$\operatorname{ext}( \pm 0.05)$} & \multirow[t]{2}{*}{ ee $( \pm 0.02)$} \\
\hline $\mathrm{C}_{12} \mathrm{E}_{8}$ & LAS & SLES & & & & & & & \\
\hline 0.25 & 0.375 & 0.375 & 85 & 19 & 0.22 & 20 & 24 & 1.28 & 1.01 \\
\hline 0.33 & 0.33 & 0.33 & 86 & 18 & 0.21 & 18 & 23 & 1.17 & 1.31 \\
\hline 0.75 & 0.125 & 0.125 & 107 & 15 & 0.14 & 18 & 25 & 1.13 & 1.42 \\
\hline
\end{tabular}
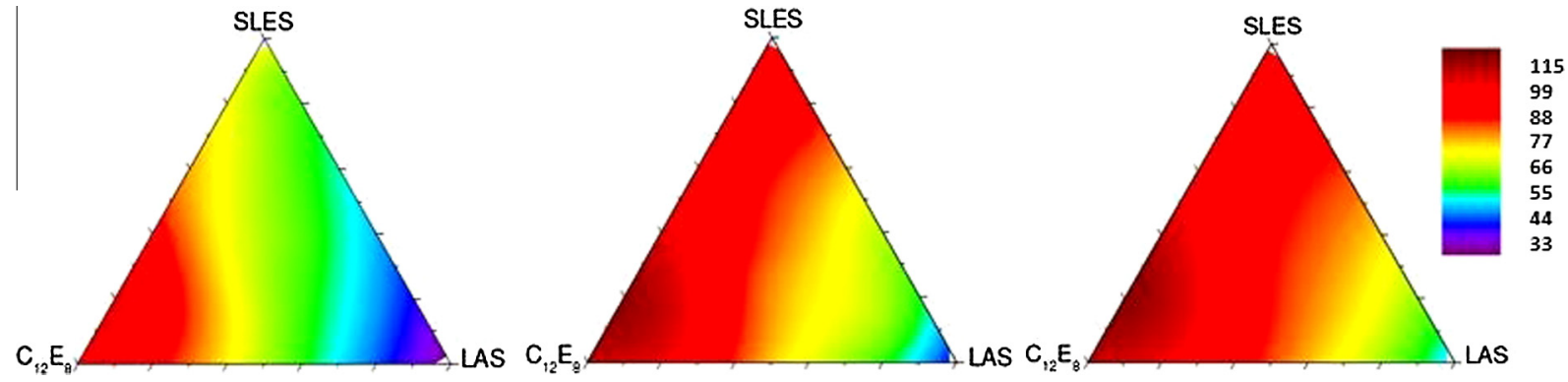

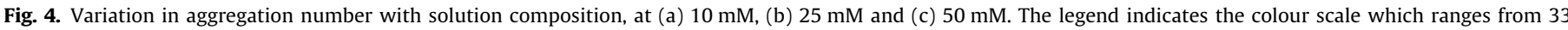
(purple) to 115 (red).

fixed mole fraction of R1/R2, 20 and $30 \mathrm{~mol} \%$, and for two different R1/R2 mol ratios, $1: 1$ and 2:1.

Over much of the solution composition range, but especially regions which are relatively rich in $\mathrm{C}_{12} \mathrm{E}_{8}$ or SLES, the resultant scattering is similar to that observed for the binary and ternary mixtures, and is consistent with interacting globular micelles. The aggregation number and other key model parameters are summarised in Table S5 in the Supporting Information for some of the data measured. In these regions the addition of R1/R2 has relatively little impact upon the form and size of the micelles. This is illustrated in Table 4 for a selected region of data at a surfactant concentration of $50 \mathrm{mM}$. The key model parameters for four different $\mathrm{C}_{12} \mathrm{E}_{8} / \mathrm{LAS} / \mathrm{SLES}$ compositions are compared with those in which $30 \mathrm{~mol} \%$ of the $\mathrm{C}_{12} \mathrm{E}_{8} / \mathrm{LAS} / \mathrm{SLES}$ mixture is replaced by a $1: 1$ mol ratio mixture of $\mathrm{R} 1 / \mathrm{R} 2$.
From Table 4 and Table S5 in the Supporting Information the addition of the R1/R2 mixture in the micellar region of the ternary $\mathrm{C}_{12} \mathrm{E}_{8} / \mathrm{LAS} / \mathrm{SLES}$ mixture has relatively little impact on the micelle aggregation number. However, the addition of the rhamnolipids results in a systematic decrease in the degree of micelle ionisation. This is consistent with the previous observations [24,25] that R1 and R2 are only weakly ionic. Although the mean aggregation numbers are not greatly affected, the geometrical parameters, $\mathrm{r}_{1}$, $r_{2}$ and ee the ellipticity ratio are different. This is due to changes in the molecular constraints in the model arising from the inclusion of R1 and R2; and this will be discussed in more detail later in the discussion

However, for solutions relatively rich in LAS, the addition of $\mathrm{R} 1 / \mathrm{R} 2$ results in a pronounced change in the solution microstructure. Replacing part of the $\mathrm{C}_{12} \mathrm{E}_{8} / \mathrm{LAS} / \mathrm{SLES}$ mixture with $\mathrm{R} 1 / \mathrm{R} 2$

Table 4

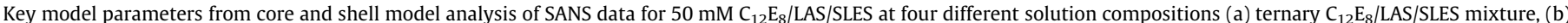
$30 \mathrm{~mol} \%$ of ternary mixture replaced by $1: 1 \mathrm{~mol}$ ratio R1/R2 mixture.

\begin{tabular}{|c|c|c|c|c|c|c|c|c|c|}
\hline \multicolumn{3}{|c|}{$\begin{array}{l}\text { Solution composition } \\
\left(\mathrm{C}_{12} \mathrm{E}_{8} / \mathrm{LAS} / \mathrm{SLES} \text { mole ratio }\right)^{\mathrm{a}}\end{array}$} & \multirow[t]{2}{*}{$v( \pm 5)$} & \multirow[t]{2}{*}{$\mathrm{z}( \pm 1)$} & \multirow[t]{2}{*}{$\delta( \pm 0.02)$} & \multirow[t]{2}{*}{$\mathrm{r} 1( \pm 1 \AA)$} & \multirow[t]{2}{*}{$\mathrm{r} 2( \pm 1 \AA)$} & \multirow[t]{2}{*}{ ext $( \pm 0.05)$} & \multirow[t]{2}{*}{ ee $( \pm 0.02)$} \\
\hline $\mathrm{C}_{12} \mathrm{E}_{8}$ & LAS & SLES & & & & & & & \\
\hline \multicolumn{10}{|c|}{ (a) Ternary mixture } \\
\hline 0.33 & 0.33 & 0.33 & 86 & 18 & 0.21 & 18 & 23 & 1.17 & 1.31 \\
\hline 0.375 & 0.375 & 0.25 & 86 & 17 & 0.20 & 18 & 23 & 1.18 & 1.31 \\
\hline 0.375 & 0.25 & 0.325 & 90 & 19 & 0.21 & 19 & 25 & 1.34 & 1.00 \\
\hline 0.25 & 0.375 & 0.375 & 85 & 19 & 0.22 & 19 & 20 & 1.28 & 1.01 \\
\hline \multicolumn{10}{|c|}{ (b) 5-component mixture } \\
\hline 0.23 & 0.23 & 0.23 & 80 & 13 & 0.16 & 17 & 21 & 1.13 & 1.70 \\
\hline 0.26 & 0.26 & 0.18 & 81 & 13 & 0.16 & 17 & 21 & 1.12 & 1.82 \\
\hline 0.26 & 0.18 & 0.26 & 82 & 13 & 0.16 & 17 & 22 & 1.14 & 1.58 \\
\hline 0.18 & 0.26 & 0.26 & 78 & 13 & 0.17 & 17 & 21 & 1.12 & 1.74 \\
\hline
\end{tabular}

\footnotetext{
${ }^{a}$ Mole fraction of total solution composition: equivalent to mole ratios in Table 4a.
} 


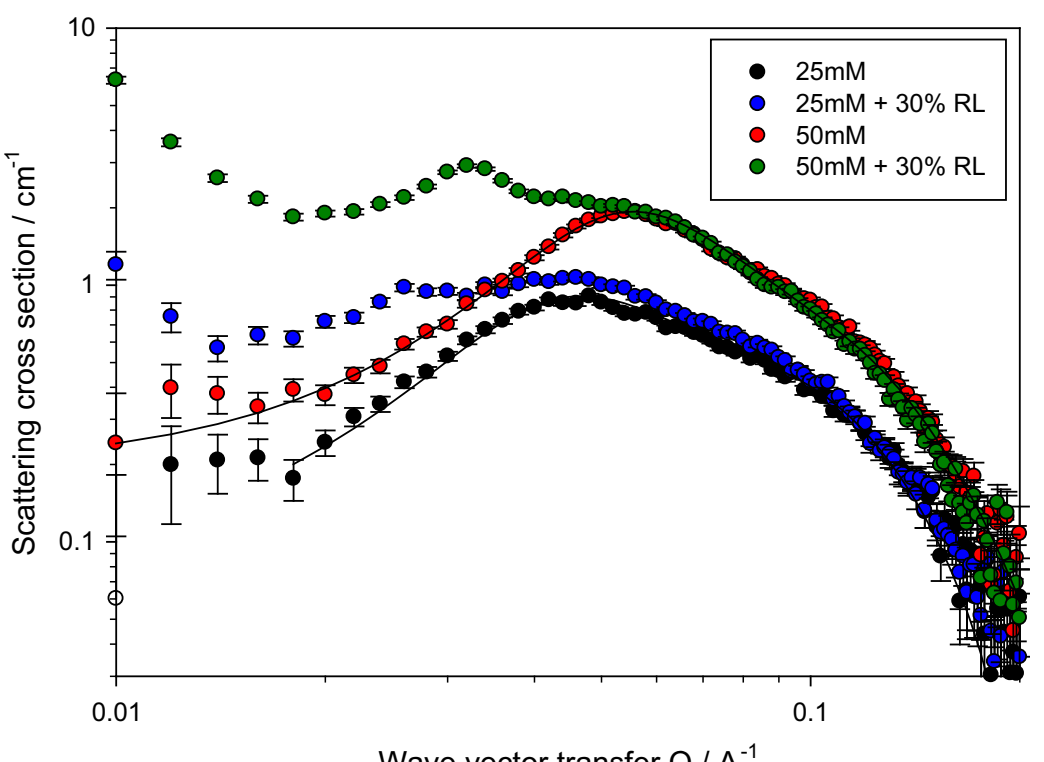

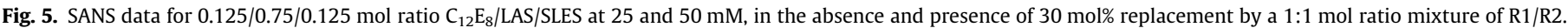
See legend for details. The solid lines are model fits as described in the text.

results in a transition from globular micelles to micellar/lamellar coexistence for LAS rich compositions. This is illustrated in Fig. 5,

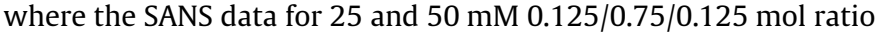
$\mathrm{C}_{12} \mathrm{E}_{8} / \mathrm{LAS} / \mathrm{SLES}$ is shown, in the absence and presence of $30 \mathrm{~mol} \%$ replacement by a $1: 1 \mathrm{~mol}$ ratio mixture of $\mathrm{R} 1 / \mathrm{R} 2$.

In the absence of the rhamnolipid the scattering from the ternary $\mathrm{C}_{12} \mathrm{E}_{8}$ /LAS/SLES mixture is consistent with globular interacting micelles, as previously presented and discussed. At both surfactant concentrations the addition of the R1/R2 mixture results in a marked change in the form of the scattering. The scattering data now indicate the onset of the formation of lamellar (vesicle) structures, and the scattering is consistent with micellar/lamellar coexistance. This is not observed in the binary or ternary mixtures in the absence of the rhamnolipids, nor in the pure component micelles in this concentration range. The addition of the rhamnolipids to the LAS rich compositions of the $\mathrm{C}_{12} \mathrm{E}_{8} / \mathrm{LAS} / \mathrm{SLES}$ ternary mixture results in a synergistic impact upon the packing and relative preferred curvature of the self-assembly to promote the transition towards more planar structures.

In light of this further SANS measurements were made in the LAS rich region of the ternary $\mathrm{C}_{12} \mathrm{E}_{8} / \mathrm{LAS} / \mathrm{SLES}$ phase diagram, see Fig. 6, in order to explore in more detail the role of the ternary composition, the R1/R2 mol ratio, and the rhamnolipid/ternary surfactant mole ratio.

The impact of the changing LAS compositions is shown in Fig. 7; where the variation in the SANS data for $50 \mathrm{mM} \mathrm{R} 1 / \mathrm{R} 2 / \mathrm{C}_{12} \mathrm{E}_{8} / \mathrm{LAS} /$ SLES is shown for a 30/70 rhamnolipid/surfactant mixture with an $\mathrm{R} 1 / \mathrm{R} 2 \mathrm{~mol}$ ratio of $1: 1$. The data are taken along a line (marked as A) in Fig. 5, for LAS compositions of $0.23,0.42,0.53$ and 0.63 , with equal mole fractions of the remaining components.

At the lowest LAS mole fraction, 0.23 , the scattering is consistent with small globular interacting micelles. Between the LAS mole fractions of 0.23 and 0.42 the form of the scattering changes, as illustrated in Fig. 7. The increase in the scattering at low $Q$ values and the appearance of first and second order Bragg peaks are indicative of the onset of a transition from micelles to more planar structures, lamellar or vesicular. The scattering then has components of both the micellar contribution at high $\mathrm{Q}$ and the lamellar component which is more visible at low $\mathrm{Q}$ and is then consistent with micellar/lamellar $\left(\mathrm{L}_{1} / \mathrm{L}_{\alpha}\right)$ coexistence. As the LAS mole fraction

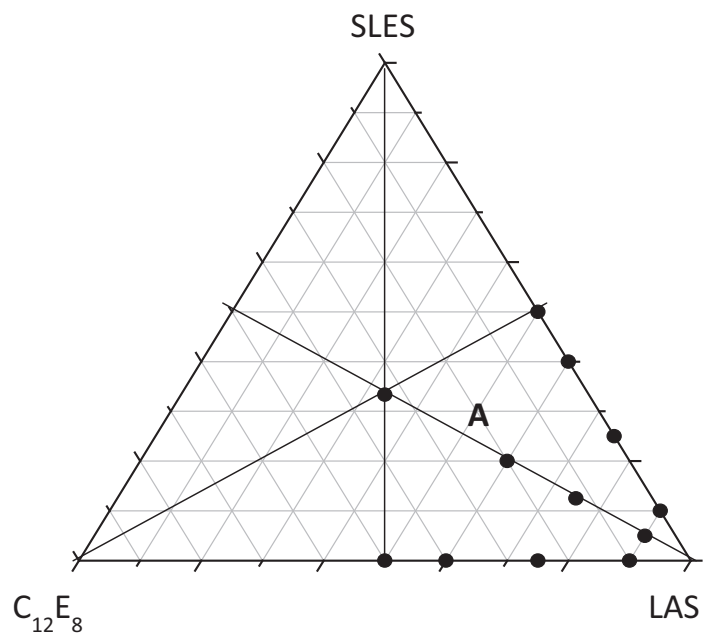

Fig. 6. Ternary diagram for $\mathrm{C}_{12} \mathrm{E}_{8} / \mathrm{LAS} / \mathrm{SLES}$, showing compositions used for more detailed evaluation of the lamellar/micellar coexistence region.

increases to 0.53 and 0.63 the lamellar component of the scattering increases and the micellar component decreases; such that at the higher LAS mole fractions the coexistence is more dominated by the lamellar structures, and is then $\mathrm{L}_{\alpha} / \mathrm{L}_{1}$. The assignment of $\mathrm{L}_{1} / \mathrm{L}_{\alpha}$ or $\mathrm{L}_{\alpha} / \mathrm{L}_{1}$ is purely qualitatively based on the relative contribution of the two scattering components.

Given that R1 like LAS has a greater tendency towards planar structures $[24,25]$ the rhamnolipid/surfactant and R1/R2 mol ratios should have an impact upon the transition from micellar to planar structures. The effect of the rhamnolipid/surfactant ratio is illustrated in Fig. 8, for the R1/R2 mol ratio of $2: 1$, a $C_{12} E_{8} / L A S / S L E S$ composition of $0.125 / 0.75 / 0.125 \mathrm{~mol}$ ratio, and at rhamnolipid/ surfactant mole ratios of $20 / 80$ and $30 / 70$, and at surfactant concentrations of 10,25 and $50 \mathrm{mM}$.

As the mole fraction of rhamnolipid increases from 20 to $30 \mathrm{~mol}$ $\%$ the lamellar component to the scattering increases significantly. As was shown also in Fig. 3 the tendency towards more planar structures increases with increasing surfactant concentration. This was observed for both LAS and R1 [24,25,43]. 


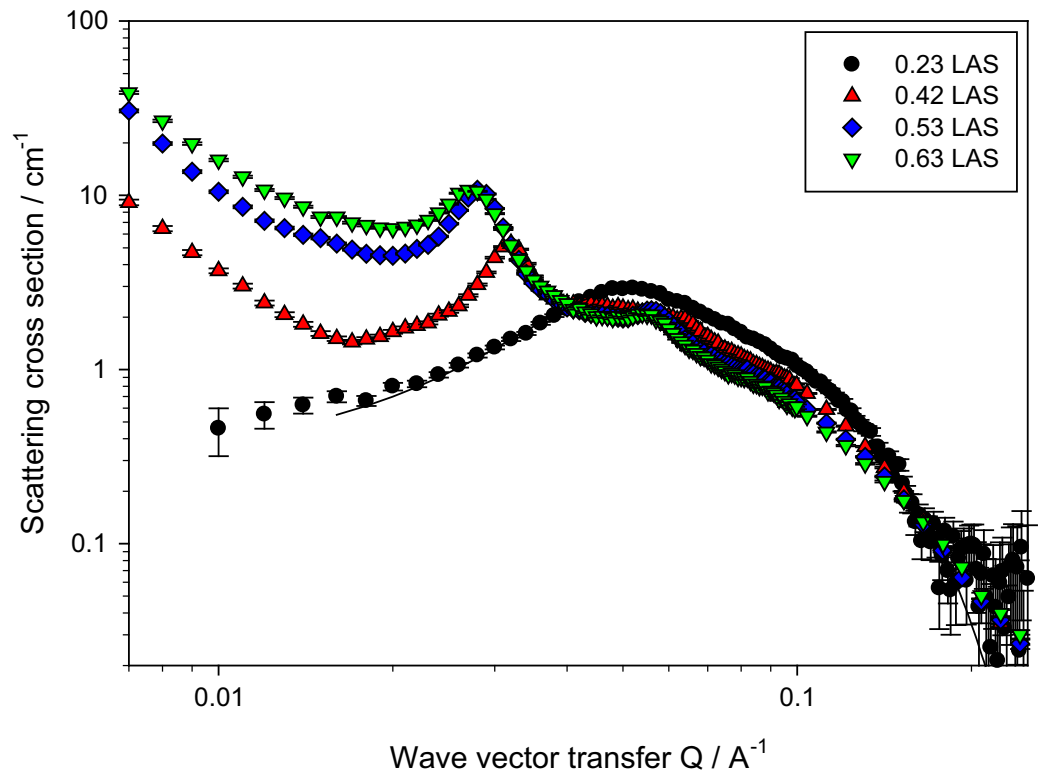

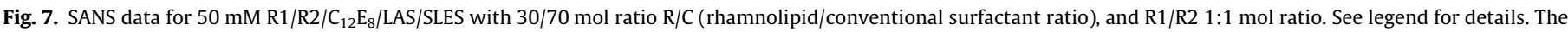

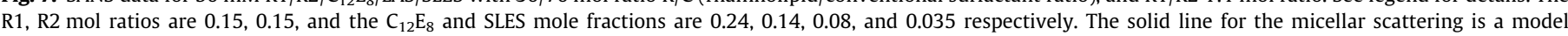
calculation as described in the main text.

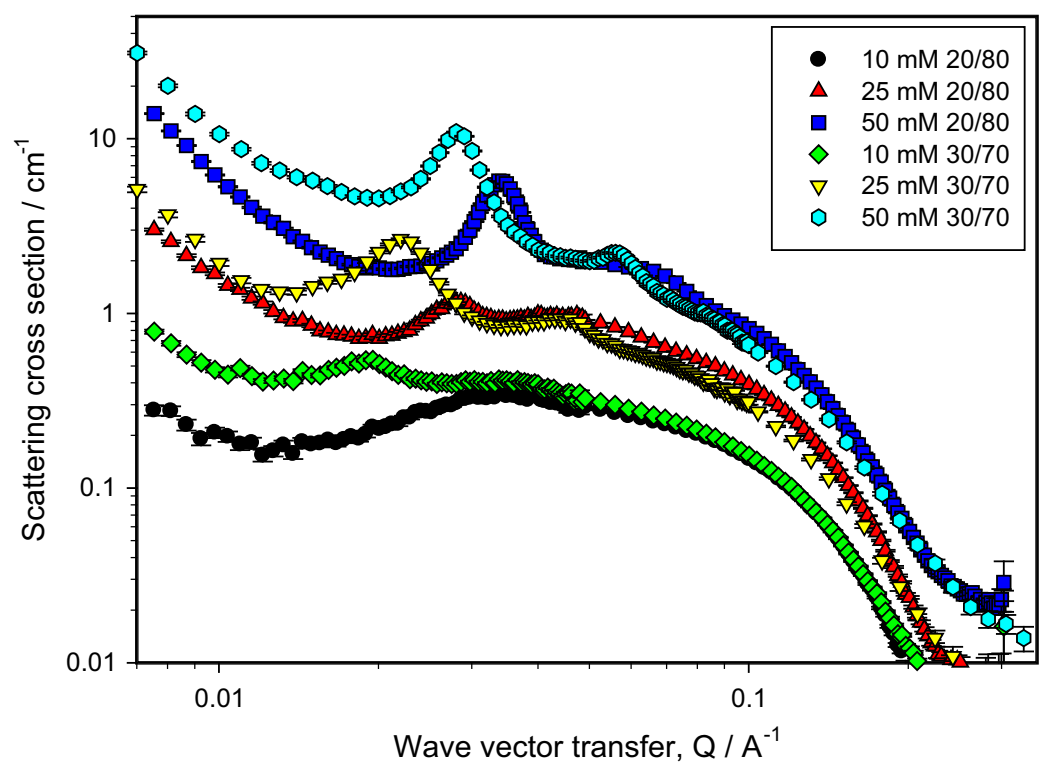

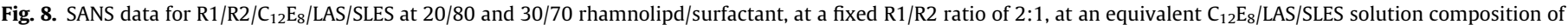
$0.125 / 0.75 / 0.125$, at 10,25 and $50 \mathrm{mM}$, see legend for details.

A similar trend is observed at a fixed rhamnolipid/surfactant ratio and composition of the $\mathrm{C}_{12} \mathrm{E}_{8}$, LAS and SLES components with increasing fraction of R1 compared to R2. This is illustrated in Fig. S4 in the Supporting Information. The data in Fig. S4 shows the SANS profiles for $\mathrm{R} 1 / \mathrm{R} 2 / \mathrm{C}_{12} \mathrm{E}_{8} / \mathrm{LAS} / \mathrm{SLES}$ at 25 and $50 \mathrm{mM}$ for a 30/70 mol ratio rhamnolipid/surfactant mixture and an equivalent ternary $\mathrm{C}_{12} \mathrm{E}_{8} / \mathrm{LAS} / \mathrm{SLES}$ mixture with a mole ratio of $0.0 / 0.75 / 0.25$, for two different R1/R2 mol ratios of $1: 1$ and $2: 1$. At the solution concentration of $25 \mathrm{mM}$ the scattering is in the form of globular micelles, whereas at $50 \mathrm{mM}$ it corresponds to $\mathrm{L}_{1} / \mathrm{L}_{\alpha}$ coexistance. However the change in the R1/R2 composition to a composition richer in $\mathrm{R} 1,2: 1$, results in a significant increase in the lamellar component at a surfactant concentration of $50 \mathrm{mM}$, and the appearance of a lamellar component at $25 \mathrm{mM}$.
At both concentrations, for the $\mathrm{R} 1 / \mathrm{R} 2 \mathrm{~mol}$ ratio of $2: 1$, the scattering is consistent with $\mathrm{L}_{\alpha} / \mathrm{L}_{1}$, lamellar/micellar, coexistance.

From the range of data obtained in the LAS rich region of the $\mathrm{C}_{12} \mathrm{E}_{8} / \mathrm{LAS} / \mathrm{SLES}$ ternary diagram, approximate phase diagrams have been determined. These show the effect of changing the rhamnolipid/surfactant mole ratio and the R1/R2 mol ratio on the formation of lamellar structures in the 5-component R1/R2/C ${ }_{12} \mathrm{E}_{8} / \mathrm{LAS} /$ SLES mixture; and are illustrated in Figs. 9a and $\mathrm{b}$.

The phase diagrams illustrate the main features and parameters associated with the transition from micellar to lamellar structures; where $\mathrm{L}_{1}$ indicates micellar, $\mathrm{L}_{1} / \mathrm{L}_{\alpha}$, micellar/lamellar coexistance where the micellar component is dominant, and, $\mathrm{L}_{\alpha} / \mathrm{L}_{1}$, lamellar/ micellar coexistance where the lamellar component is dominant. The main features are, (i) the transition from micellar to lamellar 
(a)
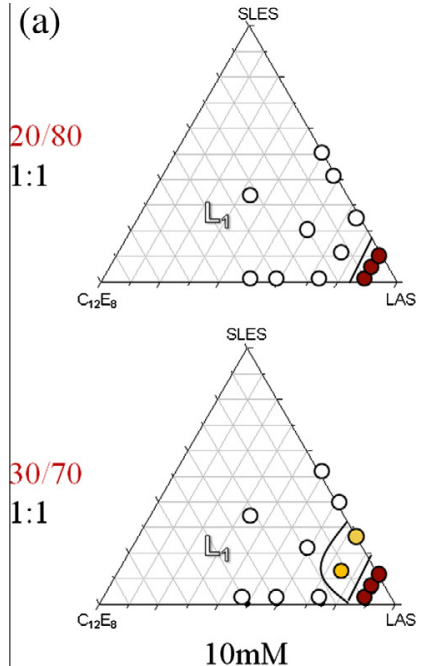

$10 \mathrm{mM}$

(b)
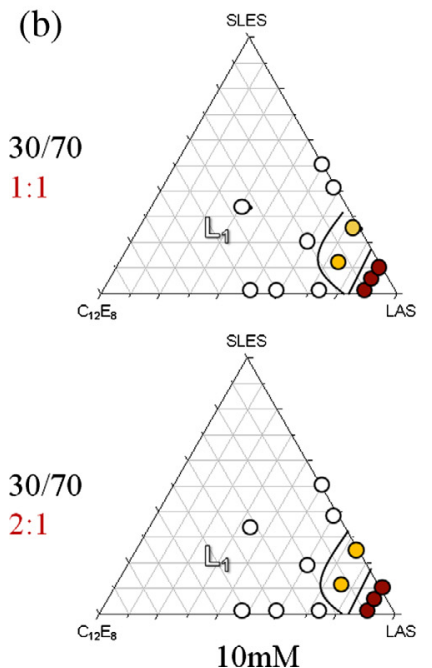
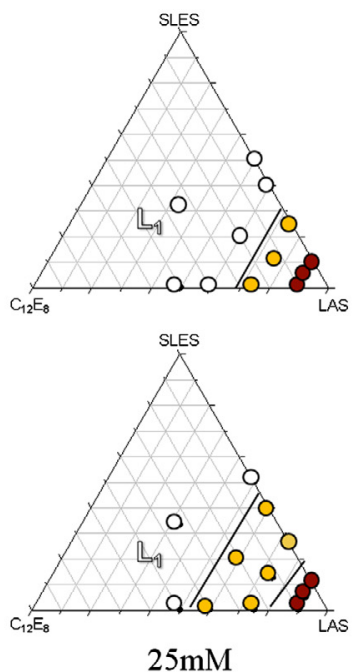

$25 \mathrm{mM}$
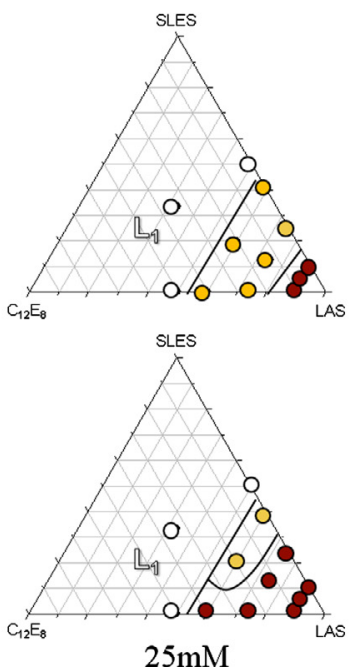
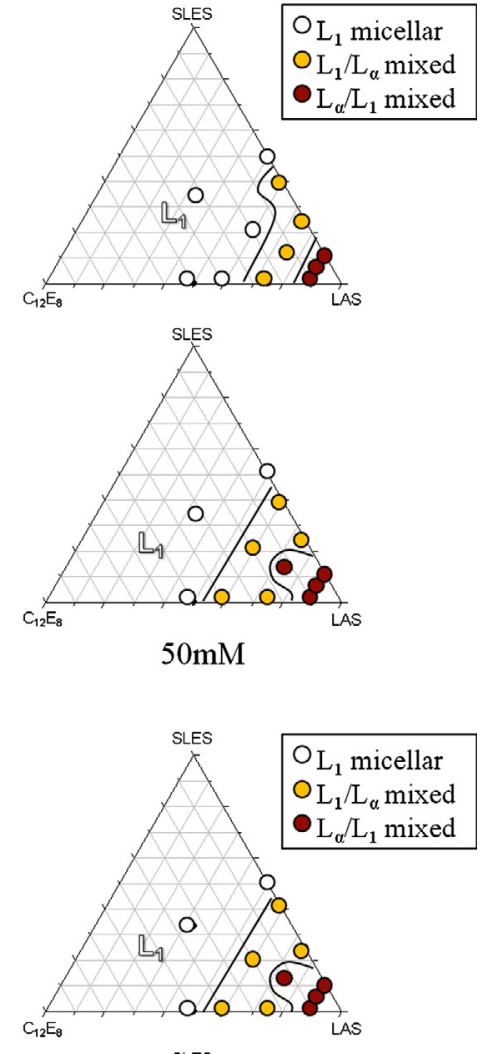

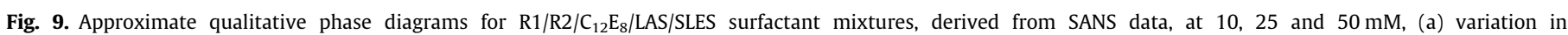
rhamnolipid/surfactant mole ratio, (b) variation in R1/R2 mol ratio.

occurs for the LAS rich region of the ternary $\mathrm{C}_{12} \mathrm{E}_{8} / \mathrm{LAS} / \mathrm{SLES}$ mixture, (ii) the transition is more pronounced as the amount of rhamnolipid increases and is only present when rhamnolipid is incorporated, (iii) the transition is more pronounced when the $\mathrm{R} 1 / \mathrm{R} 2$ ratio is richer in $\mathrm{R} 1$, and (iv) the tendency towards lamellar structures increases with increasing surfactant concentration.

\subsection{Discussion}

The scattering from the binary and ternary mixtures of $\mathrm{C}_{12} \mathrm{E}_{8} /$ LAS/SLES is consistent with globular interacting micelles, and the data are well described by the core + shell model of interacting micelles presented earlier. The consistency of the modelling supports the assumption that the micelle composition reflects the solution composition. This is as expected [29-31,41-43] at concentrations well in excess of the mixed cmc. The variation in the micelle aggregation number then reflects the aggregation number of the pure components micelles of $\mathrm{C}_{12} \mathrm{E}_{8}$ [42,43], LAS [43] and SLES [44,54], and is a composition weighted average of the pure components.

Typically LAS has a micelle packing parameter, pp $\sim 0.56$, (where the Israelachvili, Mitchell and Ninham packing parameter, pp, based on geometrical packing arguments and an effective criterion for predicting micelle morphology, $\mathrm{pp}=\mathrm{v} / \mathrm{Al}, \mathrm{v}$ is the alkyl chain molecular volume, 1 is the extended alkyl chain length and $A$ is the area/molecule, such that micelles are spherical for $\mathrm{pp}<1 / 3$, elongated for $1 / 3<\mathrm{pp}>1 / 2$ and planar for $\mathrm{pp}>1 / 2$ [56]). Although LAS micelles are globular at low concentrations [43,57], at higher there is a tendency towards planar structures [43,45], consistent with the $\mathrm{pp} \sim 0.6$. However at the concentrations studied here, up to $50 \mathrm{mM}$, only globular micelles are observed. $\mathrm{C}_{12} \mathrm{E}_{8}$, due to its relatively large ethoxylated headgroup, has a $\mathrm{pp} \sim 0.32$; and this is consistent with globular micelles, at the transition from spherical to elongated structures [42,43]. SLES [44,45] has a $\mathrm{pp} \sim 0.25$, and is in the form of globular micelles up to relatively high concentrations. The variation in the micellar geometrical parameters, as defined by the core and shell radii, $r_{1}$ and $r_{2}$, and the ellipticity, ee, reflect the molecular constraints associated with the pure components. $r_{1}$ is largest for the $C_{12} E_{8}$ and SLES rich compositions as the fully extended $\mathrm{C}_{12}$ alkyl chain length is $\sim 17 \AA$, compared to $\sim 13 \AA$ for the di- $\mathrm{C}_{6}$ chains of LAS (the values for LAS includes the phenyl ring). $r_{2}$ is largest for the $C_{12} E_{8}$ rich compositions, and this reflects the larger headgroup volume compared to SLES or LAS. The charge on the micelle, as quantified by the degree of ionisation, $\delta$, is relatively low compared to ionic surfactant micelles. It varies with micelle composition, as expected 
for ionic/nonionic mixed surfactant micelles [41-43], and is lower for the nonionic rich micelle compositions. For ionic micelles, $\delta$ is typically $\sim 0.3-0.35[46,58]$. $\delta$ has the highest value in the data presented here for LAS rich compositions, but is generally $\leqslant 0.2$. It is especially low for $\mathrm{C}_{12} \mathrm{E}_{8}$ rich compositions, as expected, but for most of the data is generally lower than that reported in other mixed systems, for example, $\mathrm{C}_{12} \mathrm{E}_{8} / \mathrm{SDS}$ [42]. This is because the degree of ionisation is also anomalously low for SLES $[54,55]$; where it is typically $\leqslant 0.15$. SLES is only weakly dissociated [54,55], and this was previously attributed to the stronger counterion binding arising from a decrease in the dielectric constant associated with the ethoxylated environment of the headgroup.

For the 5-component mixture of $\mathrm{R} 1 / \mathrm{R} 2 / \mathrm{C}_{12} \mathrm{E}_{8} / \mathrm{LAS} / \mathrm{SLES}$, over much of the composition range explored and at the relatively low surfactant concentrations used, $\leqslant 50 \mathrm{mM}$, the mixed micelles are globular interacting micelles. Furthermore the micelle aggregation number reflects the aggregation numbers of the pure component micelles as observed in the ternary mixtures. The addition of R1 and R2 has little impact on the micelle aggregation number (see Table 4). Typically the aggregation number of R1 and $\mathrm{R} 2$ are $\sim 35-45$ in this concentration range, similar to that for LAS [43] and their corresponding pp values are $\geqslant 0.5$ [24]. The molecular constraints associated with R1 and R2 have some impact upon molecular packing and hence the values of $r_{1}, r_{2}$ and ee; as the fully extended alkyl chain length associated with the di- $C_{10}$ of $R 1$ and $R 2$ is $\sim 14 \AA$ and the headgroup volumes are similar to that for $\mathrm{C}_{12} \mathrm{E}_{8}$. $\mathrm{R} 2$ with its larger di-rhamnose headgroup is fairly globular in this concentration range, whereas $\mathrm{R} 1$ has a greater tendency towards planar structures for concentrations $\geqslant 30 \mathrm{mM}$. A notable feature of the self-assembly of R1 and R2 and their mixtures is the relatively low degree of ionisation, which varies from $\sim 0.1$ for $\mathrm{R} 2$ to $\leqslant 0.2$ for $\mathrm{R} 1$ rich compositions of R1/R2 mixtures. It was observed in the study of the self-assembly and surface adsorption of R1 and R2 that they are only weakly ionic, and behave more like nonionic surfactants [24,25]. Hence a feature of the mixed micelles of $\mathrm{C}_{12} \mathrm{E}_{8} / \mathrm{LAS} / \mathrm{SLES}$ is that the low degree of ionisation is even lower when part of the $\mathrm{C}_{12} \mathrm{E}_{8} / \mathrm{LAS} / \mathrm{SLES}$ is replaced by $R 1 / R 2$. $\delta$ is then typically $\sim 0.15$, due to the effective increase in the nonionic components in the mixed micelle with the addition of R1 and R2. However, the most striking feature of the 5-component mixture is that for LAS rich compositions of the $\mathrm{C}_{12} \mathrm{E}_{8} / \mathrm{LAS} / \mathrm{SLES}$ ternary mixture, the addition of R1/R2 results in a transition towards planar lamellar/vesicular structures. Depending upon the relative amounts of LAS, R1 and R2, and the R1/R2 composition the solution microstructure is in the from of either $\mathrm{L}_{1} / \mathrm{L}_{\alpha}$ or $\mathrm{L}_{\alpha} / \mathrm{L}_{1}$ coexistance. The tendency towards the more planar structures is greater at higher surfactant concentrations, greater LAS mole fractions, and greater R1/R2 and R1 mol fractions. At the concentrations studied the transition is not observed in the binary or ternary mixtures involving $\mathrm{C}_{12} \mathrm{E}_{8}$, LAS, and SLES, nor in the R1, R2 and $\mathrm{R} 1 / \mathrm{R} 2$ solutions at concentrations relative to those in the 5-component mixtures. However it is know that LAS and R1 have a tendency towards the formation of planar structures, and which is most pronounced at higher concentrations [24,25,43,45]. The observations of the onset of the formation of planar structures in the 5-component mixtures imply that there is a synergistic packing which enhances the onset towards the planar structures associated with R1 and LAS. It occurs only for the LAS rich compositions $\mathrm{C}_{12} \mathrm{E}_{8}$ / LAS/SLES and is enhanced as the amount of R1 present increases. This is in part due to the favourable pp associated with R1 and LAS. In ionic surfactants the occurrence of more planar structures is usually associated with higher surfactant concentrations, and this is attributed to an increased electrostatic screening as the concentration increases, which helps to reduce the area/molecule, A, and increase the pp value. As $\mathrm{C}_{12} \mathrm{E}_{8}$ is nonionic, and SLES, R1 and $\mathrm{R} 2$ are only weakly ionic, the combination of $\mathrm{R} 1 / \mathrm{R} 2 / \mathrm{C}_{12} \mathrm{E}_{8} / \mathrm{LAS} / \mathrm{SLES}$ is effective in increasing the intra-micellar electrostatic repulsion, and so promote more effective headgroup packing.

\section{Conclusions}

Understanding the nature of self-assembly is important in the context of the formulation and performance of many home and personal care products. How biosurfactants interact with conventional surfactants will have a great bearing on how they can be incorporated effectively into such formulations. The SANS results presented here substantially extend the exploration of selfassembly in dilute multi-component surfactant mixtures [41-43], and the role of biosurfactants in surfactant mixing [23-27]. The SANS data show that the mixtures of $\mathrm{C}_{12} \mathrm{E}_{8}$, LAS, and SLES, a ternary mixture which is the basis of many current formulations, are consistent with globular interacting micelles with sizes and aggregation numbers that reflect a solution composition weighted average of the pure component micelles. The relatively low degree of ionisation of the micelles is consistent with the presence of the $\mathrm{C}_{12} \mathrm{E}_{8}$ nonionic surfactant and the weakly ionic nature of SLES. Upon the addition of the rhamnolipids R1 and R2 there is a transition towards planar structures when the solutions compositions are relatively rich in LAS. This is not observed in the binary and ternary mixtures of $\mathrm{C}_{12} \mathrm{E}_{8}$, LAS, and SLES or in the R1/R2 mixtures at the relatively low concentrations studied here [24,25]. Such a transition is not widely observed, and provides an insight into the packing associated with multi-component surfactant mixtures, and the potential to manipulate the preferred curvature in such mixtures. At compositions less rich in LAS, the addition of the rhamnolipids has little impact, and globular micellar structures are retained. The results illustrate that synergistic packing effects occur and can be used to tailor or manipulate microstructure; and this is a potentailly rich area for future investigations. The weakly ionic nature of the 5-component mixed micelles implies that the solutions will be relatively insensitive to the addition of electrolyte, and exhibit a high degree of tolerance to hard water; and future SANS measurements and complementary studies will be required to persue this hypothesis.

\section{Author contributions}

All the authors have given their approval of the final version of the manuscript.

\section{Funding sources}

Funded through an EPSRC CASE award with Unilever R and D, and neutron beam time provided by the ISIS and ILL facilities.

\section{Acknowledgements}

The provision of beam time at ISIS and the ILL, and the invaluable help, expertise and technical support of the facility staff is acknowledged.

\section{Appendix A. Supplementary material}

Supplementary data associated with this article can be found, in the online version, at http://dx.doi.org/10.1016/j.jcis.2016.10.071. 


\section{References}

[1] E.Z. Ron, E. Rosenberg, Natural role of biosurfactants: mini review, Environ. Microbiol. 2 (2001) 229-236.

[2] K. Muthosamy, S. Gopalakrishan, T. Kockupappy, P. Sivachidamboram, Biosurfactants: properties, commercial production and applications, Curr. Sci. 95 (2008) 736-747.

[3] J.D. Desai, I.M. Banat, Microbial production of surfactants and their commercial potential, Mol. Biol. Rev. 61 (1997) 47-64.

[4] I.M. Banat, R.S. Mukhar, S.S. Cameota, Potential commercial applications of microbial surfactants, Appl. Microbiol. Biotechnol. 53 (2000) 495-508.

[5] P. Singh, S.S. Cameotra, Potential applications of microbial surfactants in biomedical sciences, Trends Biotechnol. 22 (2004) 142-146.

[6] C.N. Milligan, Environmental applications of biosurfactants, Environ. Pollut. 113 (2005) 183-198.

[7] G. Georgiou, S.S. Lu, M.M. Sharma, Surface active components from microorganisms, Biotechnology 10 (1992) 60-65.

[8] D. Kitamoto, T. Morita, T. Fukuota, M. Konishi, T. Imura, Self-assembly properties of glycolipid biosurfactants and their potential applications, Curr. Opin. Coll. Int. Sci. 14 (2009) 315-328.

[9] M. Nitschke, S.G.V.A. O'Costa, J. Contiero, Rhamnolipid surfactants: an update on the general aspects of these remarkable biomolecules, Biotechnol. Prog. 21 (2005) 1593-1600.

[10] M.K. Batghi, M.H. Fazaelipoor, Application of rhamnolipid in the formulation of a detergent, J. Surfact. Deterg. 15 (2012) 679-684.

[11] K.K.S. Randhawa, P.K.S.M. Rahman, Rhamnolipid biosurfactants: past present and future scenario of global market, Frontiers Microbiol. 5 (2014) 1-7.

[12] A. Perfumo, M. Rudden, T.J.P. Smyth, R. Marchant, P.S. Stevenson, N.J. Parry, I. M. Banat, Rhamnolipids are conserved biosurfactant molecules: implications for their biotechnological potential, Appl. Microbiol. Biotechnol. 97 (2013) 7297-7306.

[13] A. Abolas, A. Pinazo, M.R. Infante, M. Casals, F. Garcia, A. Manresa, Physicochemical and anti-microbial properties of new rhamnolipids produced by Pseudomonas aeruginosa AT10 from soybean refinery wastes, Langmuir 17 (2001) 1367-1371.

[14] S.S. Helvaci, S. Peker, G. Ozdemir, Effects of electrolytes on the surface properties of rhamnolipids R1 and R2, Coll. Surf. B 35 (2004) 225-233.

[15] S. Peker, S.S. Helvaci, G. Ozdemir, Interface-subphase interactions in aqueous rhamnose solutions, Langmuir 19 (2003) 5838-5845.

[16] H. Zhong, G.M. Zeng, J.X. Liu, X.M. Xu, X.Y. Yuan, H.Y. Fu, G.H. Huang, Z. Liu, Y. Ding, Adsorption of monorhamnolipid and dirhamnolipid of two Pseudomonas aeruginosa strains and the effect of cell hydrophobicity, Appl. Microbiol. Biotechnol. 79 (2008) 671-677.

[17] G. Ozdemir, S. Peker, S.S. Helvaci, Effect of $\mathrm{pH}$ on the surface and interfacial behaviour of rhamnolipids R1 and R2, Coll. Surf. A 234 (2004) 135-143.

[18] Y.P. Guo, Y.Y. Hu, R.R. Ciu, H. Lu, Characterisation and micellisation of rhamnolipidic fractions and crude extracts produced by Pseudomonas aeruginosa mutant MIG-N146, J. Coll. Int. Sci. 331 (2009) 356-363.

[19] H. Wang, C.S. Cross, A. Mudalige, R.L. Polt, J.E. Pemberton, A PM-IRRAS investigation of monorhamnolipid orientation at the air-water interface, Langmuir 29 (2013) 4441-4450.

[20] M. Sanchez, K.J. Aranda, M.J. Espuny, A. Marques, J.A. Terval, A. Manresa, A. Ortz, Aggregation behaviour in a dirhamnolipid biosurfactant secreted by Pseudomonas aeruginosa in aqueous media, J. Coll. Int. Sci. 207 (2007) 246253.

[21] B. Dahranzma, C.N. Milligan, N.P. Nieh, Effects of additives on the structure of rhamnolipid (biosurfactant): a small angle neutron scattering study, J. Coll. Int. Sci. 319 (2008) 590-593.

[22] O. Pornsunthorntawee, S. Chavadej, R. Rujiravanit, Solution properties and vesicle formation of rhamnolipid biosurfactants produced by Pseudomonas aeruginosa SP4, Coll. Surf. B 72 (2009) 6-15.

[23] D. Manko, A. Zdziennicka, B. Janezuk, Thermodynamic properties of rhamnolipid micellisation and adsorption, Coll. Surf. B 119 (2014) 22-29.

[24] M.L. Chen, J. Penfold, R.K. Thomas, T.J.P. Smyth, A. Perfumo, R. Marchant, I.M. Banat, P. Stevenson, A. Parry, I. Tucker, I. Grillo, Solution self-assembly and adsorption at the air-water interface of the monorhamnose and dirhamnose rhamnolipids and their mixtures, Langmuir 26 (2010) 18281-18292.

[25] M.L. Chen, J. Penfold, R.K. Thomas, T.J.P. Smyth, A. Perfumo, R. Marchant, I.M. Banat, P. Stevenson, A. Parry, I. Tucker, Grillo, Mixing behaviour of the biosurfactant rhamnolipid with a conventional anionic surfactant, sodium dodecyl benzene sulfonate, Langmuir 26 (2010) 17958-17968.

[26] D. Song, Y. Li, S. Liang, J. Wang, Micelle behaviours of sophorolipid/ rhamnolipid binary mixed surfactant systems, Coll. Surf. A 436 (2013) 201206.

[27] E. Haba, A. Pinazo, R. Pons, L. Perez, A. Manresa, Complex rhamnolipid mixture characterisation and its influence on DPPC bilayer organisation, Biochim. Biophys. Acta 1838 (2014) 776-783.

[28] M. Abe, J.F. Scamehorn (Eds.), Mixed Surfactant Systems, Surfactant Science Series, vol. 124, Marcel Dekker, NY, 2005.
[29] P.M. Holland, Non-ideal mixed micellar solutions, Adv. Coll. Int. Sci. 26 (1986) 111-129.

[30] P.M. Holland, D.N. Rubingh, Non-ideal multi-component mixed micelle model, J. Phys. Chem. 87 (1983) 1984-1990.

[31] P.M. Holland, Non-ideality at the interface in mixed micellar systems, Coll. Surf. 19 (1986) 171-183.

[32] A. Shiloach, D. Blankschtein, Predicting micellar properties of binary surfactant mixtures, Langmuir 14 (1998) 1618-1631.

[33] R.F. Kamrath, E.I. Franses, Mass-action model in mixed micellisation, J. Phys. Chem. 88 (1984) 1642-1648.

[34] J.R. Lu, R.K. Thomas, J. Penfold, Surfactant layers at the air-water interface: structure and composition, Adv. Coll. Int. Sci. 84 (2000) 143-304.

[35] J. Penfold, R.K. Thomas, Mixed surfactant at the air-water interface, Annu. Rep. Prog. Chem. Sect. C 106 (2010) 14-35.

[36] J. Penfold, R.K. Thomas, The limitations of models of surfactant mixing at interfaces, as revealed by neutron scattering, PCCP 15 (2013) 7017-7027.

[37] J.D. Hines, R.K. Thomas, P.R. Garrett, G.K. Rennie, J. Penfold, A study of the interactions in a ternary surfactant systems in micelles and adsorbed layers, J. Phys. Chem. B 102 (1998) 9708-9713.

[38] E. Staples, L. Thompson, I. Tucker, J. Penfold, Effect of dodecanol on mixed nonionic and non-ionic/anionic adsorption at the air-water interface, Langmuir 10 (1994) 4136-4141.

[39] J. Liley, J. Penfold, R.K. Thomas, I. Tucker, J.T. Petkov, P. Stevenson, J.R.P. Webster, Surface adsorption in ternary surfactant mixtures, J. Phys. Chem. B, submitted for publication.

[40] J. Liley, J. Penfold, R.K. Thomas, I. Tucker, J.T. Petkov, P. Stevenson, I. Banat, R Marchant, M. Rudden, J.R.P. Webster, Adsorption at the air-water interface in biosurfactant-surfactant mixtures, J. Phys. Chem. B, submitted for publication.

[41] J. Penfold, E. Staples, L. Thompson, I. Tucker, J. Hines, R.K. Thomas, J.R. Lu, N Warren, The structure and composition of mixed surfactant micelles of SDS/ $\mathrm{C}_{12} \mathrm{E}_{6}$ and $\mathrm{C}_{12} \mathrm{E}_{6} / \mathrm{C}_{16} \mathrm{TAB}$, J. Phys. Chem. B 103 (1999) 5204-5211.

[42] J. Penfold, I. Tucker, R.K. Thomas, E. Staples, R. Schuermann, Structure of mixed anionic/non-ionic surfactant micelles: experimental observations relating to the role of the headgroup electrostatic and steric effects and the effects of added electrolyte, J. Phys. Chem. B 109 (2005) 10760-10770.

[43] J. Penfold, R.K. Thomas, C.C. Dong, I. Tucker, K. Metcalfe, S. Golding, I. Grillo, Equilibrium surface adsorption behaviour in complex anionic/non-ionic surfactant mixtures, Langmuir 23 (2007) 10140-10149.

[44] J.T. Petkov, I. Tucker, J. Penfold, R.K. Thomas, D.N. Petsev, C.C. Dong, S. Golding, I. Grillo, The impact of multivalent counterions $\mathrm{Al}^{3+}$ on the surfactant adsorption and self-assembly of anionic surfactant alkyloxyethylene sulphate and anionic/non-ionic surfactant mixtures, Langmuir 26 (2010) 16669-16709.

[45] J.G. Ma, B.J. Boyd, C.J. Drummond, Positional isomers of linear sodium dodecyl benzene sulfonate, solubility, self-assembly and air-water interfacial activity, Langmuir 22 (2006) 8646-8654.

[46] J.B. Hayter, J. Penfold, Determination of micelle structure and charge by small angle neutron scattering, Colloid Polym. Sci. 261 (1983) 1022-1030.

[47] J.B. Hayter, J. Penfold, An analytic structure factor for macroion solutions, Mol. Phys. 42 (1981) 109-118.

[48] J.B. Hayter, J.P. Hansen, A rescaled MSA structure factor for dilute charged colloidal dispersions, Mol. Phys. 46 (1982) 651-656.

[49] R.K. Heenan, J. Penfold, S.M. King, SANS at pulsed neutron sources: present and future prospects, J. Appl. Cryst. 30 (1997) 1140-1147.

[50] R.K. Heenan, S.M. King, D.S. Turner, J.R. Treadgold, SANS2D at the ISIS 2nd target station, Proc. ICANS XVII (2006) 780-785.

[51] C.D. Dewhurst, D33, a third small angle neutron scattering instrument at the ILL, Meas. Sci. Technol. 19 (2008) 034007-034011.

[52] R.E. Ghosh, S.U. Egelhaaf, A. Rennie, ILL Internal Report, ILL98GH14T, 1989.

[53] R.K. Heenan, S.M. King, R. Osborn, H.B. Stanley, RAL Internal Report, RAL$89,128,1989$.

[54] H. Xu, J. Penfold, R.K. Thomas, J.T. Petkov, I. Tucker, I. Grillo, A. Terry, Impact of $\mathrm{Al}^{3+}$ on the self-assembly of the anionic surfactant sodium polyethylene glycol monoalkyl ether sulphate in aqueous solution, Langmuir 29 (2013) 1335913366.

[55] H. Xu, K. Ma, P.X. Li, R.K. Thomas, J. Penfold, J.R. Lu, Limitations in the application of the Gibbs equation to anionic surfactants at the air-water interface: SDS and SLES above and below the cmc, Langmuir 29 (2013) 93359351.

[56] J.N. Israelachvili, D.J. Mitchell, B.W. Ninham, Theory of self-assembly of hydrocarbon amphiphiles into micelles and bilayers, J. Chem. Soc. Faraday Trans. 2 (72) (1976) 1525-1568.

[57] E. Caponetti, R. Triolo, O.C. Ho, J.S. Johnson, L.J. Magid, P. Butler, K.A. Payne, A small angle neutron scattering (SANS) study of micellar structure and growth of a straight chain benzene sulfonate: comparison with an isomeric branched chain surfactant, J. Coll. Int. Sci. 116 (1987) 200-210.

[58] J.B. Hayter, A self-consistent theory of dressed micelles, Langmuir 8 (1992) 2873-2876. 